and II ; the ratio is actually much less (whether calculated from specific or absolute activities).

It seems likely that the turnover of free glycine is higher in pupæ that are in the process of forming the adult than in pupæ that are still in diapause. We tentatively draw the conclusion that, on the average during the 24-hr. experimental period, the specific radioactivity of the free glycine in the free amino-acid pool was rather lower in Sphinx III than in Sphinx IV and $V$, and consequently the mean specific rate of non-blood protein synthesis from free glycine is much higher in the transforming pupa than in the diapausing animal. This seems to support the view of adult protein synthesis directly from the free amino-acid pool.

We wish to thank $\mathrm{D}_{\mathrm{r}}$. $J$. Leclereq for rearing the insects and for helpful discussion of the results.

$$
\begin{aligned}
& \text { S. BricteuX-Grigome } \\
& \text { W. G. Verty } \\
& \text { M. FLorkin } \\
& \text { Department of Biochemistry, } \\
& \text { University of Liège. } \\
& \text { Jan. 17. } \\
& \text { 'Moore, S., and Stein, W. H., J. Biol. Chem., 192, } 663 \text { (1951). }
\end{aligned}
$$

\section{Indoleacetic Acid in Two Species of Nicotiana}

IN Nature, and afterwards elsewhere, Vlitos, Meudt and Beimler ${ }^{12}$ reported that they were unable to detect indole-3-acetic acid in leaf, stem, root or apical tissue of Nicotiana tabacum L. 'Maryland Mammoth' plants, which had been grown under long-day conditions.

The absence from a plant of indole-3-acetic acid, which is considered a major plant hormone, is of interest, and its absence from a variety of tobacco was of particular interest to us, because in this laboratory it had been shown that stems and leaves of $N$. tabacum 'Virginia Gold' contained this acid in concentrations up to $10 \mu \mathrm{gm}$. $/ \mathrm{kgm}$. of fresh weight (unpublished data).

As 11-week old plants of N. tabacum 'Maryland Mammoth' were available, it was thought desirable to find out if these plants contained indole-3-acetic acid. The 'Maryland Mammoth' plants had been grown together with Nicotiana sylvestris Speg. and Comes under short-day ( $8 \mathrm{hr}$. : daylight) or long-day (16 hr.: daylight supplemented by incandescent lamps) conditions. Half the plants of each species in each light treatment had been inoculated with tobacco mosaic virus, the other half being maintained as controls. At 11 weeks, all plants had about twelve visible leaves; the 'Maryland Mammoth' plants were $18 \mathrm{~cm}$. high under long day and $45 \mathrm{~cm}$. high and flowering under short day. $N$. sylvestris plants were $75 \mathrm{~cm}$. high and flowering under long day and were rosettes under short day.

From five plants of each treatment the upper eight leaves (lengths : $5-30 \mathrm{~cm}$.) and the stems were harvested separately, and the acidic ether-soluble growth-substances (from approximately $60 \mathrm{gm}$. tissue) were extracted and chromatographed (solvent: isopropanol : water : ammonium hydroxide, $10: 1: 1$ by the method of Kefford ${ }^{3}$, which is almost identical with that of Vlitos et al. ${ }^{2}$. The chromatograms were sectioned and the sections were biologically assayed with the Avena coleoptile section extension test ${ }^{3}$.

The Avena extension tests showed, on chromatograms of all extracts, an area of growth promotion corresponding to the position of a synthetic indole-3 acetic acid guide $\left(R_{F} \quad 0 \cdot 3\right)$. Thus, the acid was detected in the stem and leaves of plants of $N$. tabacum 'Maryland Mammoth' and N. sylvestris grown under both short- and long-day conditions and whether non-inoculated or inoculated with tobacco mosaic virus. The concentration of indole-3-acetic acid in non-inoculated plants was of the order of l $\mu \mathrm{gm} . / \mathrm{kgm}$. of fresh weight of tissue. Additional assays of tobacco plant material grown between June and November under natural daylight conditions showed that indole-3-acetic acid occurred in leaves and stems of (1) 'Maryland Mammoth' plants 19 weeks old (non-flowering); (2) N. tabacum 'Turkish Samsun' plants 15 weeks old (flowering).

In addition to indole-3-acetic acid, a growth-promoter, $R_{F} 0 \cdot 0-0 \cdot 15$, and a growth-inhibitor, $R_{F} 0 \cdot 5-$ $0 \cdot 7$, were detected in all extracts. No sign was found of the auxin of $R_{F} 0.98$ detected by Vlitos et al. ${ }^{2}$, in extracts of 'Maryland Mammoth' leaves and apices.

The different findings of Vlitos et al. and ourselves must be associated with differences either in technique of auxin extraction and detection, or in the physiological status of the plants used. One difference in technique is that Vlitos et al. ${ }^{2}$ evaporate extracts "in a stream of air", which may oxidize indole-3acetic acid, but if this is the case it is still necessary to explain the appearance of the auxin of $R_{F} 0.98$, and why this is not oxidized also. If the tissues extracted by Vlitos et al. contained a concentration of indole-3-acetic acid much less than $1 \mu \mathrm{gm} . / \mathrm{kgm}$. as found here, their colorimetric method may not have been sensitive enough, in the presence of other extracted materials, to detect the amounts of indole3 -acetic acid present, notwithstanding the use of extracts from up to $1 \mathrm{kgm}$. of tissue. At present there is no clue to physiological differences, but they seem unlikely to be related either to the age of the plants (temporal or physiological) or to the reproductive status.

\section{N. P. KeFFORD}

Katie HeLMS

Division of Plant Industry,

Commonwealth Scientific and

Industrial Research Organization, Canberra.

Jan. 4.

${ }^{1}$ Vlitos, A. J., Meudt, W., and Beimler, R., Nature, 177, 890 (1956). 2 Vlitos, A. J., Meudt, W, and Beimler, R., Contrib. Boyce Thompson Inst., 18,' 283 (1956).

3 Kefford, N. P., J. Exp. Bot., 6, 129 (1955).

\section{Nature of Chloragogen Granules}

Ir has become generally accepted that the chloragogenous tissue of earthworms is excretory in function and that the granules consist chiefly of guanine. This view is to be found in both elementary and more advanced text-books and is based on the work of Willem and Minne ${ }^{1}$. Theirs is not the only work, however, and during the first decades of this century a number of papers were published on this problem. The evidence supporting the excretory nature of the chloragogen is conflicting and that for the alternative theory of the elaboration and storage of food reserves is equally contradictory. Many new techniques have been developed since this early work and it seemed desirable to re-investigate the problem using modern methods. Moreover, past work was 